\title{
The Danish National Registry for Biological Therapy in Inflammatory Bowel Disease
}

This article was published in the following Dove Press journal:

Clinical Epidemiology

25 October 2016

Number of times this article has been viewed

\author{
Lone Larsen' \\ Michael Dam Jensen ${ }^{2}$ \\ Michael Due Larsen ${ }^{3}$ \\ Rasmus Gaardskær Nielsen ${ }^{4}$ \\ Niels Thorsgaard ${ }^{5}$ \\ Ida Vind ${ }^{6}$ \\ Signe Wildt ${ }^{7}$ \\ Jens Kjeldsen ${ }^{8}$ \\ 'Department of Gastroenterology \\ and Hepatology, Aalborg University \\ Hospital, Aalborg, ${ }^{2}$ Department \\ of Internal Medicine, Section of \\ Gastroenterology, Lillebaelt Hospital \\ Vejle, Vejle, ${ }^{3}$ Department of Clinical \\ Research, Faculty of Health Sciences, \\ University of Southern Denmark, \\ ${ }^{4}$ Department of Paediatrics, Hans \\ Christian Andersen Children's \\ Hospital, Odense University \\ Hospital, Odense C, ${ }^{5}$ Department \\ of Internal Medicine, Section of \\ Gastroenterology, Hospital Unit \\ West, Herning, ${ }^{6}$ Department of \\ Gastroenterology, Copenhagen \\ University Hospital, Hvidovre, \\ ${ }^{7}$ Department of Medicine, Section \\ of Gastroenterology, Køge Hospital, \\ Køge, ${ }^{8}$ Department of Medical \\ Gastroenterology, Odense University \\ Hospital, Odense C, Denmark
}

Correspondence: Lone Larsen Department of Gastroenterology and Hepatology, Aalborg University Hospital, Mølleparkvej 4, DK-9000 Aalborg,

Denmark

Tel +4597663500

Fax +4597663577

Email lone.larsen@rn.dk
Aim: The aims of The Danish National Registry for Biological Therapy in Inflammatory Bowel Disease are to ensure that biological therapy and the clinical management of patients with inflammatory bowel disease (IBD) receiving biological treatment are in accordance with the national clinical guidelines and, second, the database allows register-based clinical epidemiological research.

Study population: The study population comprises all Danish patients with IBD (both children and adults) with ulcerative colitis, Crohn's disease, and IBD unclassified who receive biological therapy. Patients will be enrolled consecutively when biological treatment is initiated.

Main variables: The variables in the database are: diagnosis, time of diagnosis, disease manifestation, indication for biological therapy, previous biological and nonbiological therapy, date of visit, clinical indices, physician's global assessment, pregnancy and breastfeeding (women), height (children), weight, dosage (current biological agent), adverse events, surgery, endoscopic procedures, and radiology.

Descriptive data: Eleven clinical indicators have been selected to monitor the quality of biological treatment. For each indicator, a standard has been defined based on the available evidence. National results will be published in an annual report and local results on a quarterly basis. The indicators will be reported as department-specific proportions with $95 \%$ confidence intervals, and the national average will be provided for comparison. An estimated 1,200-1,300 new biological therapies are initiated each year in Danish patients with IBD.

Conclusion: The database will be available for research during 2016. Data will be made available by The Danish Clinical Registries (www.rkkp.dk).

Keywords: inflammatory bowel disease, biological therapy, anti-TNF- $\alpha$ agents, quality indicators, database

\section{Background}

The incidence of inflammatory bowel disease (IBD) is increasing worldwide including Denmark. ${ }^{1-4}$ During the last decades, introduction of biological therapy has changed the management of ulcerative colitis (UC) and Crohn's disease (CD). ${ }^{5}$ As a consequence, the medication-related expenses of IBD therapy have increased substantially. ${ }^{6}$ International and national treatment guidelines support clinicians in treatment decisions and rational clinical use of biological therapy and are used by health care providers to prioritize and regulate the costs of therapy.

\section{Aim of The Danish National Registry for Biological Therapy in Inflammatory Bowel Disease}

To ensure a rational use of biological drugs and adherence to national guidelines, The Danish National Registry for Biological Therapy in Inflammatory Bowel Disease 
(BIO-IBD) has been established in 2015. First, the aim of the database is to ensure that the choice of biological therapy and the clinical management of patients with IBD receiving biological treatment are in accordance with the national clinical guidelines ${ }^{7}$ and second, the database can be used for register-based clinical epidemiological research.

The database is planned to start in March 2016, and patients will be enrolled consecutively when biological treatment is initiated. Based on recent data from The Danish National Patient Registry (NPR), we estimate that 1,200-1,300 new biological therapies are initiated each year and at a given point in time 2,700-2,800 patients are treated with biological agents.

\section{Study population}

In Denmark (population of $\sim 5.5$ million people), all citizens have free access to a tax-supported health care system, and biological therapy is only administered in public hospitals without cost to the patient. ${ }^{8}$

For all Danish hospitals, both public and private, it is mandatory by Danish law to report diagnosis and clinical procedures to NPR. The completeness of coding in NPR is very high as $99 \%$ of all hospital discharges and out-patient clinics from somatic hospitals are recorded. ${ }^{9}$ Likewise the completeness of diagnoses of IBD in NPR is very good. In one study, the validity of the IBD diagnoses in NPR was examined using the pathology system as a reference standard, confirming that $94 \%$ of the UC and CD diagnoses were included in the NPR. The overall validity of diagnoses of CD in the NPR was $97 \%$, and for UC $90 \% .{ }^{10}$ Identification of patients is based on the Danish Civil Registration System (CRS). The CRS has registered all persons alive and living in Denmark since 1968, and has a very high accuracy of Danish citizens and migrations. ${ }^{11,12}$

The availability of these nationwide Danish registries makes it possible to retrieve data on almost all patients with IBD and treatment with biological agents. Hence, the study population comprises all Danish patients with IBD (both children and adults) with UC, CD, and IBD-unclassified (IBD-U) who receive biological therapy. Patients will be enrolled consecutively when biological treatment is initiated. Eligible patients with IBD are bio-naive patients (patients never treated with biological therapy); patients previously treated with biological therapy and stopped for $>3$ months, and patients already on biological therapy who, due to side effects or lack of effect, switch to another biological drug.

It is mandatory for the departments prescribing biological therapy to report these data to the BIO-IBD registry.

\section{Quality indicators}

Eleven quality indicators have been defined (Table 1). Choice, background, and level of evidence for the indicators

Table I Quality indicators

\begin{tabular}{|c|c|c|}
\hline Quality indicator & $\begin{array}{l}\text { Indicator } \\
\text { standard (\%) }\end{array}$ & $\begin{array}{l}\text { Type of } \\
\text { indicator }\end{array}$ \\
\hline $\begin{array}{l}\text { ICD: Percentage of patients with luminal CD for whom the indication for biological therapy } \\
\text { is in accordance with the national guidelines }\end{array}$ & $\geq 80$ & Process \\
\hline $\begin{array}{l}\text { 2CD: Percentage of CD patients with no prior biological therapy for whom the selected first- } \\
\text { line biological therapy is in accordance with the national guidelines }\end{array}$ & $\geq 80$ & Process \\
\hline $\begin{array}{l}\text { 3CD: Percentage of patients with CD in maintenance therapy with a biological agent, who have a } \\
\text { minimum of two outpatient visits per year }\end{array}$ & $\geq 80$ & Process \\
\hline $\begin{array}{l}\text { 4CD: Percentage of patients in maintenance therapy with a biological agent, diagnosed with } \\
\text { luminal } C D \text {, never having undergone surgery for } C D \text {, who have well-controlled disease } \\
(\mathrm{HBI} \text { score }<5 \text { or abrPCDAI }<10)\end{array}$ & $\geq 60$ & Outcome \\
\hline $\begin{array}{l}\text { 5UC: Percentage of patients with UC for whom the indication for biological therapy is in } \\
\text { accordance with the national guidelines }\end{array}$ & $\geq 80$ & Process \\
\hline $\begin{array}{l}\text { 6UC: Percentage of UC patients with no prior biological therapy and chronic active disease } \\
\text { for whom the selected first-line biological therapy is in accordance with the national guidelines }\end{array}$ & $\geq 80$ & Process \\
\hline $\begin{array}{l}\text { 7IBD: Percentage of UC patients with acute severe ulcerative colitis for whom the selected } \\
\text { first-line biological therapy is in accordance with the national guidelines }\end{array}$ & $\geq 80$ & Process \\
\hline $\begin{array}{l}\text { 8UC: Percentage of patients with UC in maintenance therapy with a biological agent, who have a } \\
\text { minimum of two outpatient visits per year }\end{array}$ & $\geq 80$ & Process \\
\hline $\begin{array}{l}\text { 9UC: Percentage of patients with UC in maintenance therapy with a biological agent, who have } \\
\text { well-controlled disease (SCCAI }<5 \text { or PUCAI }<10)\end{array}$ & $\geq 60$ & Outcome \\
\hline $\begin{array}{l}\text { IOIBD: Percentage of patients with UC or CD, who are in steroid free remission after at least } \\
6 \text { months of biological therapy }\end{array}$ & $\geq 40$ & Outcome \\
\hline $\begin{array}{l}\text { I IIBD: Percentage of children with UC or CD in maintenance therapy with a biological agent, } \\
\text { for whom data on height and weight is recorded in minimum two outpatient visits per year }\end{array}$ & $\geq 60$ & Process \\
\hline
\end{tabular}

Abbreviations: abrPCDAI, Abbreviated Pediatric Crohn's Disease Activity Index; CD, Crohn's disease; HBI, Harvey-Bradshaw Index; IBD, inflammatory bowel disease; PUCAI, Pediatric Ulcerative Colitis Index; SCCAI, Simple Clinical Colitis Activity Index; UC, ulcerative colitis. 


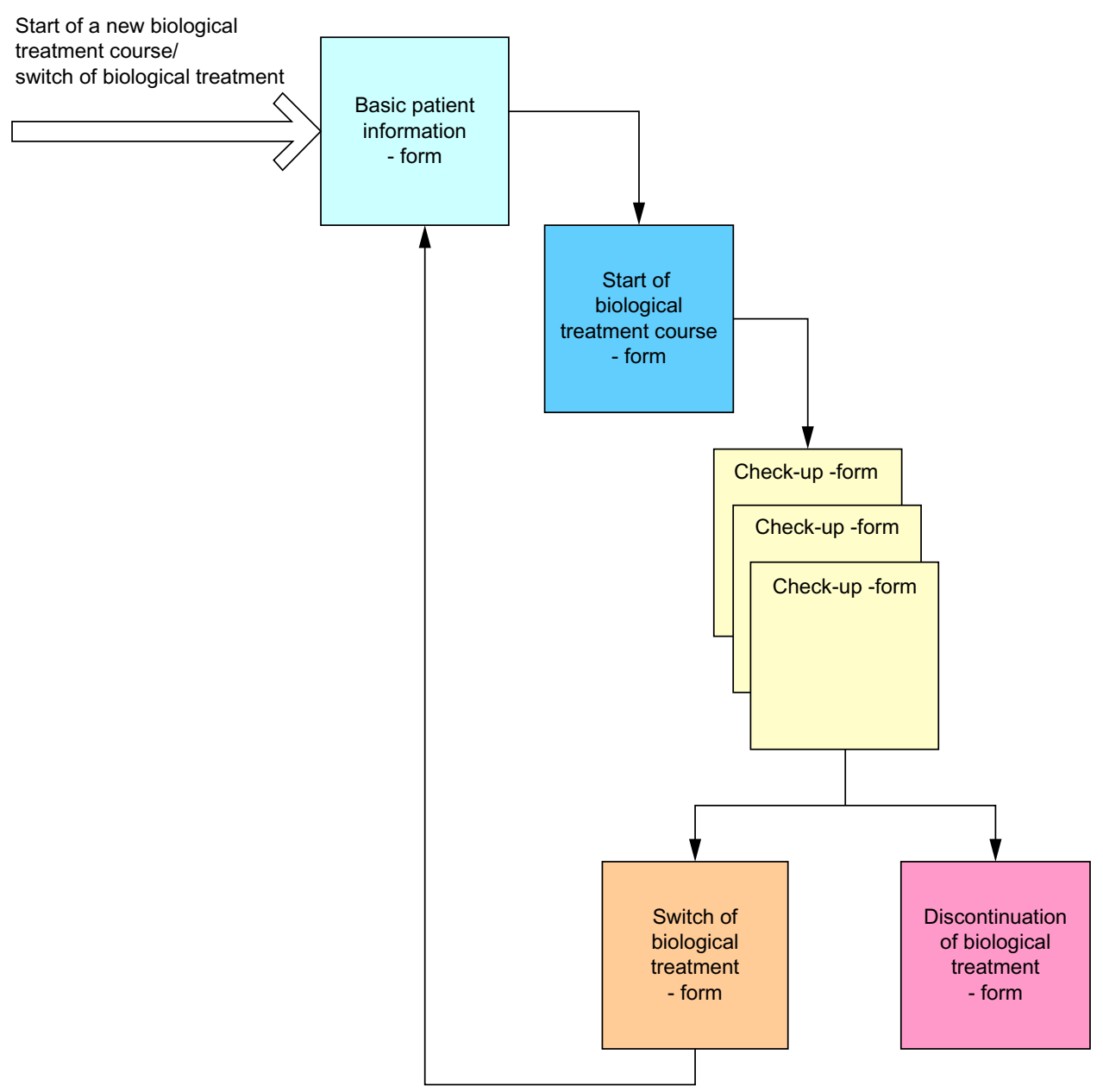

Figure I Patient flow in the database.

Notes: Patients will be included at start or switch of biological therapy. A form for basic patient information, start of biological therapy, outpatient visit where biological therapy will be administered, switch of therapy, and discontinuation of biological therapy will be available at relevant time-point in course of therapy.

are described in The BIO-IBD Documentarist Report. ${ }^{13}$ Indicators related to outcome represent clinically relevant measures, with indicator standards determined from existing literature. Indicators related to process are addressing guideline adherence and administrative issues, with indicator standards determined from consensus in the working group.

In the future, new quality indicators are to be defined and added to the registry.

\section{Main variables}

The variables in the database are obtained by two methods: Data from NPR are used for registration of the IBD patient and basic information on diagnosis, use of biologic agent, and IBD-related procedures. This is supplemented with clinical information reported by the clinician using a national webbased input module (Supplementary materials $\underline{1}, \underline{2}$, and $\underline{3}$ ). This is believed to ensure the best possible data quality.

1. Data harvested from NPR: diagnosis, previous biological therapy, surgery, endoscopic procedures, radiology, treatment dates regarding current biological therapy, and current biological agent (Table 2).

2. Data reported by the clinician include: background information (diagnosis, time of diagnosis, disease manifestation, indication for biological therapy, and previous nonbiological therapy) and contact data at outpatient visit (date of the visit, relevant clinical indices [see later], physician's global assessment, pregnancy/breastfeeding [women], height [children], weight, dosage [current biological agent], nonbiological therapy, adverse events with regard to the biological agent, and treatment decision on continuing, changing, or stopping the biological agent).

3. The clinical indices used in the database are:

- Harvey-Bradshaw Index for $\mathrm{CD}^{14}$

- Abbreviated Pediatric Crohn's Disease Activity Index for children with $\mathrm{CD}^{15}$

- Simple Clinical Colitis Activity Index for UC and IBD-U ${ }^{16}$ 
- Pediatric Ulcerative Colitis Activity Index for children with UC and IBD-U ${ }^{17}$

- Short Health Scale. ${ }^{18,19}$

A complete list of the variables can be found in Supplementary material 2 .

\section{Data recording}

The clinician is required to ensure that every eligible patient is entered into the database upon start of biological therapy. It is recommended that data are entered in the database every time biological treatment is administered, but as a minimum twice yearly and every time changes in therapy, or side-effects occur or if therapy is stopped. In addition to this, there is a continuous data collection from the NPR, which will ensure that all eligible patients are registered, should the clinician fail to include the patient at the first visit. To ensure the completeness of the database, the departments involved in administering biological treatment will receive lists of patients with records of biological treatment codes from the NPR.

The quality of data in the database relies entirely on the clinician/IBD nurse and is the responsibility of the department giving biological treatment. It will only be possible to calculate the quality indicators if sufficient data is reported in the database. If it is not possible to calculate the indicators, the departments with incomplete data will be mentioned in the annual report. There is no official quality control but as the results are a public document and reported on a quarterly basis to the departments to regularly review their clinical performance, it is believed to motivate the clinicians to high quality in both treatment and reporting.

\section{Examples of research}

The database will be available for research during 2016. Data will be made available by The Danish Clinical Registries (RKKP; www.rkkp.dk).

\section{Administrative issues and funding}

The database is administered by a steering committee, which comprises:

- Five members of the Danish Society of Gastroenterology and Hepatology (one member from each of the five regions in Denmark)

- A pediatric gastroenterologist, member of the Danish Pediatric Society

- A documentarist (clinician to compose a report on the background and evidence for the indicators)
Table 2 Codes from The Danish National Patient Registry to be included in the Danish Registry for Biological Therapy: ICD-10 diagnostic codes used to identify patients with IBD

\begin{tabular}{|c|c|c|}
\hline Crohn's disease & \multicolumn{2}{|l|}{ K50.0-50.9 } \\
\hline Ulcerative colitis & \multicolumn{2}{|l|}{ K5I.0-5I.9 } \\
\hline IBD unclassified & \multicolumn{2}{|l|}{ K51.9, K52.9 } \\
\hline Specific drug coding: & & $\begin{array}{l}\text { ATC-coding used with } \\
\text { procedures: }\end{array}$ \\
\hline $\mathrm{BOHJI8AI}$ & Infliximab & L04AA 12 or L04AB02 \\
\hline BOHJI8A3 & Adalimumab & L04AA 17 or L04AB04 \\
\hline $\mathrm{BOHJI8A4}$ & Golimumab & L04AB06 \\
\hline $\mathrm{BOHJ} / 8 \mathrm{~A} 5$ & Certolizumab pegol & L04AB05 \\
\hline $\mathrm{BOH} 26$ & Natalizumab & L04AA23 \\
\hline $\mathrm{BOHJI9H4}$ & Vedolizumab & L04AA33 \\
\hline \multicolumn{3}{|l|}{ Operation codes } \\
\hline KJFB00 & \multicolumn{2}{|l|}{ Small bowel resection } \\
\hline KJFBOI & \multicolumn{2}{|c|}{ Laparoscopic small bowel resection } \\
\hline KJFB20 & \multicolumn{2}{|l|}{ lleocecal resection } \\
\hline KJFB2I & \multicolumn{2}{|c|}{ Laparoscopic ileocecal resection } \\
\hline KJFB30 & \multicolumn{2}{|c|}{ Right side hemicolectomy } \\
\hline KJFB3I & \multicolumn{2}{|c|}{ Laparoscopic right side hemicolectomy } \\
\hline KJFB33 & \multicolumn{2}{|c|}{ Other resection of small bowel or colon } \\
\hline KJFB34 & \multicolumn{2}{|c|}{$\begin{array}{l}\text { Other laparoscopic resection of small bowel or } \\
\text { colon }\end{array}$} \\
\hline KJFB40 & \multicolumn{2}{|c|}{ Resection of transverse colon } \\
\hline KJFB4I & \multicolumn{2}{|c|}{ Laparoscopic resection of transverse colon } \\
\hline KJFB43 & \multicolumn{2}{|c|}{ Left side hemicolectomy } \\
\hline KJFB44 & \multicolumn{2}{|c|}{ Laparoscopic left side hemicolectomy } \\
\hline KJFB46 & \multicolumn{2}{|c|}{ Resection of sigmoid colon } \\
\hline KJFB47 & \multicolumn{2}{|c|}{ Laparoscopic resection sigmoid colon } \\
\hline KJFB50 & \multicolumn{2}{|c|}{ Other resection of colon } \\
\hline KJFB5 I & \multicolumn{2}{|c|}{ Other laparoscopic resection of colon } \\
\hline KJFB60 & \multicolumn{2}{|c|}{ Resection of sigmoid colon with colostomy } \\
\hline KJFB6I & \multicolumn{2}{|c|}{$\begin{array}{l}\text { Laparoscopic resection of sigmoid colon } \\
\text { colostomy and distal closure }\end{array}$} \\
\hline KJFB63 & $\begin{array}{l}\text { Other colon resecti } \\
\text { closure }\end{array}$ & lostomy an distal \\
\hline KJFB64 & $\begin{array}{l}\text { Other laparoscopic } \\
\text { colostomy and dista }\end{array}$ & $\begin{array}{l}\text { resection with } \\
\text { ure }\end{array}$ \\
\hline KJFB96 & Other gut resection & \\
\hline KJFB97 & Other laparoscopic & esection \\
\hline KJFHOO & Colectomy and ileor & stoma \\
\hline KJFHIO & Colectomy and ileos & \\
\hline KJFHII & Laparoscopic colect & and ileostomy \\
\hline $\mathrm{KJFH} 20$ & Proctocolectomy an & stomy \\
\hline $\mathrm{KJFH} 96$ & Other colectomy & \\
\hline KJGBO0 & Resection of rectum & \\
\hline KJGBOI & $\begin{array}{l}\text { Laparoscopic resect } \\
\text { or coloanal anastom }\end{array}$ & f rectum with colorectal \\
\hline KJGBIO & Resection of rectum & colostomy \\
\hline KJGBII & Laparoscopic resecti & f rectum with colostomy \\
\hline KJGB30 & Abdominoperianal $r$ & ion of rectum \\
\hline KJGB3। & Laparoscopic and per & excision of rectum \\
\hline MRI & & \\
\hline UXMD & MRI of abdomen anc & \\
\hline UXMDIO & MRI of upper abdom & \\
\hline UXMDI5 & MRI of lower abdom & ncluding pelvis \\
\hline UXMD20 & MRI of retroperiton & \\
\hline
\end{tabular}

(Continued) 
Table 2 (Continued)

\begin{tabular}{|c|c|}
\hline UXMD22 & MRI of abdominal wall \\
\hline UXMD25 & MRI of gastrointestinal tract \\
\hline UXMD25A & MRI of small bowel \\
\hline UXMD25B & MRI of colon \\
\hline \multicolumn{2}{|l|}{ CT scan } \\
\hline UXCD & CT scan of abdomen and pelvis \\
\hline UXCD00 & CT scan of abdomen \\
\hline UXCDIO & CT scan of upper abdomen \\
\hline UXCDI5 & CT scan of lower abdomen, including pelvis \\
\hline \multicolumn{2}{|l|}{ Endoscopy } \\
\hline KUJ & Endoscopy of gastrointestinal tract \\
\hline KUJC & Esophageal endoscopy \\
\hline KUJC02 & Esophageal endoscopy \\
\hline KUJC05 & Esophageal endoscopy with biopsy \\
\hline $\mathrm{KUJCl} 2$ & Flexible esophageal endoscopy \\
\hline KUJCI5 & Flexible esophageal endoscopy with biopsy \\
\hline KUJF32 & Colonoscopy \\
\hline KUJF35 & Colonoscopy with biopsy \\
\hline KUJF42 & Sigmoideoscopy \\
\hline KUJF45 & Sigmoideoscopy with biopsy \\
\hline KUJFI2 & Enteroscopy through stoma \\
\hline KUJFI5 & Enteroscopy through stoma with biopsy \\
\hline KUJF92 & Capsule enteroscopy \\
\hline KUJF82 & Double balloon endoscopy \\
\hline KUJF85 & Double balloon endoscopy with biopsy \\
\hline \multicolumn{2}{|c|}{ Chest X-ray } \\
\hline UXRCO0 & X-ray of chest \\
\hline UXRC05 & $X$-ray of chest \\
\hline \multicolumn{2}{|c|}{ Abdominal X-ray } \\
\hline UXRD & Abdominal X-ray \\
\hline UXRDI5 & Small bowel follow-through \\
\hline UXRD20 & Small bowel follow-through with contrast in tube \\
\hline UXRD35 & Pouchografi \\
\hline UXZI6 & Fistulography \\
\hline
\end{tabular}

Notes: Treatment codes used to identify eligible patients with IBD. Codes used for surgery, radiology, and endoscopic procedures.

Abbreviations: ATC, anatomical therapeutical chemical classification; CT, computed tomography; IBD, inflammatory bowel disease; ICD, The International Classification of Diseases; MRI, magnetic resonance imaging.

- A RKKP-team (Danish Clinical Quality Databases represented by the Centre of Competence for Nationwide Clinical Registries) assigning a contact person, a data manager, an epidemiologist, and a statistician.

The members are appointed for a period of 4 years by the board of the respective societies. There is an option for one re-election.

The steering committee has no financial means of its own, but the Danish Regions' funding for clinical quality registries has secured a grant for the establishment of the database.

The BIO-IBD database operates under the Danish law on data protection, with license granted by the Danish Data Protection Agency and the Danish National Board of Health. Further individual patient consent or Ethical Review Board approval is not required according to Danish law when data are used to monitor, secure, and improve clinical quality.

\section{Conclusion}

Based on the indicators defined, an annual report will state the quality of biological therapy in patients with IBD treated in Denmark, both at a national and department level together with a complete overview of the data available.

In addition, results are reported on a quarterly basis to the departments to regularly review their clinical performance. The indicators will be reported as department-specific proportions with $95 \%$ confidence intervals, and the national average will be provided for comparison. For each indicator, a standard has been developed based on the available evidence.

\section{Acknowledgments}

The authors would like to thank all members of the steering committee for their contribution in the development the BIO-IBD database. The members of the steering committee are Data Manager, Pia Andersen, MSc, Katrine Abildtrup Nielsen, MSc in Health Science, Esra Öztoprak, MSc in Health Science, all from The Danish Clinical Registries a National quality improvement program, Statistician Jan Nielsen, MSc, PhD, and Bente Nørgaard, MD, PhD, DMSc. This paper was funded by the Program for Clinical Research Infrastructure (PROCRIN) established by the Lundbeck Foundation and the Novo Nordisk Foundation and administered by the Danish Regions.

\section{Disclosure}

The authors report no conflicts of interest in this work.

\section{References}

1. Vind I, Riis L, Jess T, et al. Increasing incidences of inflammatory bowel disease and decreasing surgery rates in Copenhagen City and county, 2003-2005: a population-based study from the Danish Crohn colitis database. Am J Gastroenterol. 2006;101(6):1274-1282.

2. Jacobsen BA, Fallingborg J, Rasmussen HH, et al. Increase in incidence and prevalence of inflammatory bowel disease in northern Denmark: a population-based study, 1978-2002. Eur J Gastroenterol Hepatol. 2006;18(6):601-606.

3. Jakobsen C, Paerregaard A, Munkholm P, et al. Pediatric inflammatory bowel disease: Increasing incidence, decreasing surgery rate, and compromised nutritional status: a prospective population-based cohort study 2007-2009. Inflamm Bowel Dis. 2011;17(12):2541-2550.

4. Norgard BM, Nielsen J, Fonager K, Kjeldsen J, Jacobsen BA, Qvist N. The incidence of ulcerative colitis (1995-2011) and Crohn's disease (1995-2012) - based on nationwide Danish registry data. J Crohns Colitis. 2014;8(10):1274-1280.

5. Rungoe C, Langholz E, Andersson M, et al. Changes in medical treatment and surgery rates in inflammatory bowel disease: a nationwide cohort study 1979-2011. Gut. 2014;63(10):1607-1616. 
6. Baggrundsnotat for terapiområdet biologisk behandling af kroniske inflammatoriske tarmsygdomme. rådet for anvendelse af dyr sygehusmedicin; 2015. Available from: http://www.regioner.dk. Accessed June 9, 2015.

7. DSGH guidelines. Available from: http://www.dsgh.dk/home/ guidelines. Accessed June 9, 2015.

8. Christiansen T. Organization and financing of the Danish health care system. Health Policy. 2002;59(2):107-118.

9. Andersen TF, Madsen M, Jorgensen J, Mellemkjoer L, Olsen JH. The Danish National Hospital Register. A valuable source of data for modern health sciences. Dan Med Bull. 1999;46(3):263-268.

10. Fonager K, Sorensen HT, Rasmussen SN, Moller-Petersen J, Vyberg M. Assessment of the diagnoses of Crohn's disease and ulcerative colitis in a Danish hospital information system. Scand J Gastroenterol. 1996;31(2):154-159.

11. Pedersen CB. The Danish civil registration system. Scand J Public Health. 2011;39(7 Suppl):22-25.

12. Schmidt M, Pedersen L, Sorensen HT. The Danish civil registration system as a tool in epidemiology. Eur J Epidemiol. 2014;29(8): 541-549.
13. Jensen M. Databasen for biologisk behandling af inflammatoriske tarmsygdomme. Dokumentalistrapport. Available from: http://www. rkkp.dk. Accessed June 9, 2015.

14. Harvey RF, Bradshaw JM. A simple index of Crohn's-disease activity. Lancet. 1980;1(8167):514.

15. Griffiths AM, Otley AR, Hyams J, et al. A review of activity indices and end points for clinical trials in children with Crohn's disease. Inflamm Bowel Dis. 2005;11(2):185-196.

16. Walmsley RS, Ayres RC, Pounder RE, Allan RN. A simple clinical colitis activity index. Gut. 1998;43(1):29-32.

17. Turner D, Otley AR, Mack D, et al. Development, validation, and evaluation of a pediatric ulcerative colitis activity index: a prospective multicenter study. Gastroenterology. 2007;133(2):423-432.

18. Stjernman H, Granno C, Jarnerot G, et al. Short health scale: a valid, reliable, and responsive instrument for subjective health assessment in Crohn's disease. Inflamm Bowel Dis. 2008;14(1):47-52.

19. Hjortswang H, Jarnerot G, Curman B, et al. The short health scale: a valid measure of subjective health in ulcerative colitis. Scand $J$ Gastroenterol. 2006;41(10):1196-1203.
Clinical Epidemiology

\section{Publish your work in this journal}

Clinical Epidemiology is an international, peer-reviewed, open access, online journal focusing on disease and drug epidemiology, identification of risk factors and screening procedures to develop optimal preventative initiatives and programs. Specific topics include: diagnosis, prognosis, treatment, screening, prevention, risk factor modification,

Submit your manuscript here: http://www.dovepress.com/clinical-epidemiology-journal

\section{Dovepress}

systematic reviews, risk \& safety of medical interventions, epidemiology \& biostatistical methods, and evaluation of guidelines, translational medicine, health policies \& economic evaluations. The manuscript management system is completely online and includes a very quick and fair peer-review system, which is all easy to use. 